\title{
Existenzsicherung im Öffentlichen Recht
}

\author{
Minimum - Grundlagen - Förderung
}

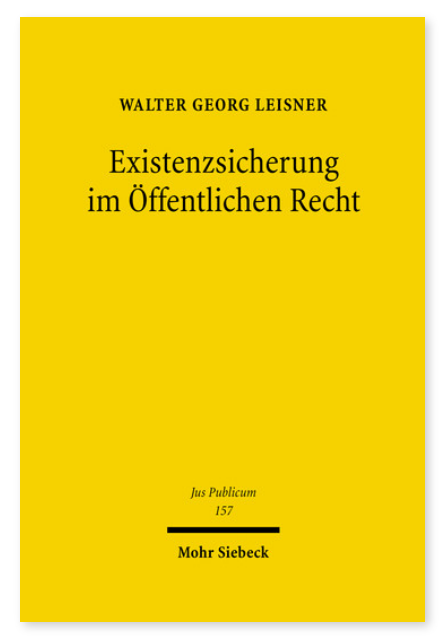

2007. XXXIII, 530 Seiten. JusPubl 157

ISBN 978-3-16-151238-4

DOI 10.1628/978-3-16-151238-4

eBook PDF 159,00€

ISBN 978-3-16-149289-1

Leinen $159,00 €$
Walter Georg Leisner stellt die hochaktuelle Problematik der Existenzsicherung in ihrer historischen Entwicklung aus kirchlicher Karitas, Wohlfahrtsstaatlichkeit und Armenfürsorge dar. Dabei untersucht er ihre geistesgeschichtlichen Hintergründe bis hin zur Existenzphilosophie.

Davon ausgehend entwickelt der Autor Grundlinien einer Dogmatik der Existenzsicherung, die auf dem Schutz des Existenzminimums, der Existenzgrundlagen und der Existenzförderung basiert. Normative Grundlagen finden sich im Verfassungsrecht, im Satz von der Menschenwürde sowie in zentralen Grundrechten, wie etwa dem Recht auf Leben oder der Berufsfreiheit. Das Bundesverfassungsgericht verpflichtet insbesondere die staatliche Steuergewalt auf den Schutz des Existenzminimums.

Ihren Schwerpunkt findet Existenzsicherung im Öffentlichen Recht: Im Sozialrecht, im Abgabenrecht, im Asyl- und Ausländerrecht sowie im Subventionsrecht soll elementaren Lebensbedürfnissen Rechnung getragen werden. Sogar im Zivilrecht sichern dies die Pfändungsgrenzen und das Verbot der Knebelungsverträge. All diese vielfältigen, aber normativ zersplitterten Regelungen müssen zusammengesehen und koordiniert werden. Dabei möchte Walter Georg Leisner kein ökonomisches Minimum bestimmen, wohl aber Wertigkeiten und Prioritäten aufzeigen, die dabei zu beachten sind.

Walter Georg Leisner Geboren 1973; Studium der Rechtswissenschaften in München und Hamburg; 2002 Promotion; 2006 Habilitation; seit 2001 Rechtsanwalt in München.

Jetzt bestellen:

https://mohrsiebeck.com/buch/existenzsicherung-im-oeffentlichen-recht-9783161512384?no_cache=1 order@mohrsiebeck.com

Telefon: +49 (0)7071-923-17

Telefax: $+49(0) 7071-51104$ 